\title{
Sobre o poder das mulheres no aforismo 68 de $A$ Gaia Ciência
}

\author{
Adriana Delbó ${ }^{1}$
}

Resumo: Este texto está vinculado a uma investigação contemporânea dos problemas de gênero a partir de Nietzsche, visando pensar se naquilo que já está dado como mulher não há a obediência a ideais que exigem que a cada gênero seja necessário atender às amarras que significam exatamente impedimentos à criação de si. Tomando como principal referência o aforismo 68 de A Gaia Ciência, pretendo discutir as cenas e os diálogos elaborados por Nietzsche, os quais desbancam a discussão que os homens travam para a determinação das mulheres. Contrapõe-se a isso, o poder das mulheres de elaborarem-se a si mesmas. Trata-se de uma leitura que vê em Nietzsche contribuições para a análise das dicotomias de gênero como determinações daquilo que se é, e, consequentemente, a impossibilidade para que cada pessoa possa fazer-se para além do que já está autorizado pelas sociedades.

Palavras-chave: Ideais - Dicotomia de gênero - Determinações - Criação de si

\section{On the Power of Women in Aphorism 68 of The Gaia Science}

\begin{abstract}
This text is linked to a contemporary investigation of gender problems from Nietzsche, thinking if someone who is already woman does not have an obedience to ideals that are required of each gender necessary to tied that what mean exactly impediments to self-creation. As the main reference of the aphorism 68 of The Gay Science, I intend to discuss scenes and dialogues elaborated by Nietzsche, who overcome a discussion that men initiate to determine women. Contrasted to this, the power of women to elaborate themselves. It is a reading that see in Nietzsche contribution to an analysis of gender dichotomies, as determinations of what it is, and, consequently, an impossibility for each person who goes beyond what is already authorized by societies.
\end{abstract}

Keywords: Ideals - Gender dichotomy - Determinations - Self-creation.

\footnotetext{
${ }^{1}$ Professora da Universidade Federal de Goiás (UFG). E-mail: delbo@ufg.br
} 


\section{Introdução}

Como sabemos, já são muitas e cada vez mais atuais as pesquisas no campo da Filosofia e das Ciências Humanas cujas preocupações convergem em torno das análises do feminismo e das relações de gênero. Tais relações, infelizmente, não se alteram no mesmo ritmo com que tais pesquisas se desenvolvem. Simultaneamente e, muitas vezes em conflito, elas caminham sem necessárias colaborações. É desafiador também o esforço para lidar com escritos cujas ideias parecem ser avessas ao feminismo, com estilo aparentemente contrário às mulheres, tal como o "tom" que pode ressoar nas leituras do que Nietzsche deixou sobre o assunto.

Entretanto, faz-se necessário reconhecer que os termos "mulher", "mulheres" e "feminismo", na obra de Nietzsche, ocorrem de modo plural e até mesmo controverso; por vezes aparecem em meio a aparentes elogios; por vezes aparecem de modo provocativo, outras vezes, ainda, sequer tais avaliações são imediatamente possíveis. Parece não faltar razões para incômodos. Nem sempre é evidente se ele está se referindo a uma concepção própria ou da tradição, com a qual concorda ou está criticando. É que a respeito das idealizações para a mulher, ele escreve de modo também genealógico, a fim de colocar em questão os fundamentos que pretendam sustentar tais ideais sem assumirem por quais propósitos tentam alçá-los. Meu objetivo, neste momento, é retomar alguns dos aforismos de Nietzsche que interpreto como análises dele dos ideais construídos pela tradição e que denunciam as autoridades que compõem as célebres dicotomias "homem" e "mulher". Neste sentido, compreendo que Nietzsche não escreve sobre o que é a mulher, ou o que elas devem ser, ou sobre o que ele sente por mulheres. Ele traz concepções, constrói cenas, diálogos, personagens, comparações e contraposições, a fim de deixar ser sentido e percebido o quanto as considerações a respeito de "mulher" podem estar presas a construções baseadas em demandas localizadas em um oposto ${ }^{2}$.

Em vista disso, uma leitura feminista e contemporânea de Nietzsche possa talvez contribuir para o que Joan Scott defendeu em seu texto, Gênero: uma categoria de análise histórica, qual seja: a "necessidade de uma rejeição do caráter fixo e permanente da oposição binária, de uma historicização e de uma desconstrução genuínas dos termos da diferença sexual (...). Devemos encontrar formas (mesmo que imperfeitas) de submeter sem cessar nossas categorias à crítica e nossas análises à autocrítica". Recorrendo a Derrida, Scott propõe que "essa crítica significa analisar, levando em conta o contexto, a forma pela qual opera qualquer oposição binária, revertendo e deslocando sua construção hierárquica, em vez de aceitá-la como real ou autoevidente ou como fazendo parte da natureza das coisas". Ela alega também que "é evidente que, num certo sentido, as feministas vêm fazendo isso por muitos anos. A história do pensamento feminista é uma história da recusa da construção hierárquica da relação entre masculino e feminino, em seus contextos específicos, e uma tentativa para reverter ou deslocar suas operações"’3.

A respeito das contribuições de Nietzsche para a quebra dos alicerces que sustentam tais oposições, retomo as contribuições de Isadora Petry, no artigo intitulado "Supondo que a

\footnotetext{
${ }^{2}$ Esta minha análise compõe um projeto maior de pesquisa em desenvolvimento intitulado, "Nietzsche e as mulheres: uma leitura feminista da crítica nietzschiana aos ideais", cadastrado na Faculdade de Filosofia da Universidade Federal de Goiás (UFG).

${ }^{3}$ SCOT"T, "Gênero: uma categoria útil de análise histórica", p. 84.
} 
verdade seja uma mulher: para uma ética da diferença a partir de Nietzssche", no qual vejo o destaque a um dos cernes do pensamento deste filósofo para tal discussão, qual seja: de que a "crença nas oposições, seja entre bem e mal, entre masculino e feminino, seria uma crença própria de um modo de pensar metafísico, e predominantemente executado por homens ao longo da história da filosofia ocidental"4. Além de ser crença na metafísica, ainda se trata de algo feito e sustentado por homens. Não faltam motivos para as mulheres não darem seguimento a isso. Não obstante, Petry também traz um alerta importante e bastante caro ao pensamento de Nietzsche: "pensar que não há tal oposição necessária entre as coisas não é o mesmo que pensar que não há diferenças, pelo contrário 5 ".

É necessário não só compreender e considerar as diferenças, mas, sobretudo, dar vazão às diferenças. Isso, a meu ver, contribui para uma política feminista, cujo poder não estaria à mercê das diminuições e não revezaria de uma compreensão para outra, de uma força para outra. Um poder de elaboração de si estaria em cena. Nesta, o poder das oposições perderia espaço. Pensar nisso pode ser possível também a partir da obra de Nietzsche, na qual os termos "mulher", "mulheres", "feminino" aparecem em distintos contextos e com múltiplas problemáticas. Não são poucas suas denúncias aos efeitos perniciosos das crenças nos conceitos, nas ideias, nas concepções, nas palavras, nas elaborações teóricas, nos consensos mobilizados pela vontade de verdade. Assim, a relação com o que se tem como já dado, já construído, como verdade, não pode se dar sem lançar mão da crítica, tendo em vista o que, junto a toda essa construção, é erguido e é sustentado, por meio das circunstâncias, das forças, dos afetos, da moralidade constitutiva de todas essas produções. Em Nietzsche, encontramos a possibilidade de investigar quais ideias, concepções, expectativas, autorizações e dificuldades envolvem o que é chamado e tratado enquanto "feminino", "mulher", "mulheres". Para ele, nada disso é apartado e é isento de necessidades, de interpretações inerentes a tudo o que participa de tais feitos. Consequentemente, acreditar e aceitar o poder de determinação dos nomes, das palavras, dos ideais, é conduzir adiante uma obra que não necessariamente é de própria autoria.

Faz-se relevante retomar aforismos escritos por Nietzsche, nos quais ele problematiza os ideais para o que "deve ser" a mulher e analisar, assim, nos diálogos e nas comparações trazidas por ele, quais as demandas de quem fala sobre as mulheres, desprezando-as e/ou tentando definir, decidir, delimitar, e, por fim, construir para elas ideais a serem perseguidos, para que possam ser bem avaliadas. Há uma chave de leitura nietzschiana que precisa ser acionada no que diz respeito ao que ele escreve sobre as mulheres, qual seja: a genealogia. Por isso, tem relevância sua crítica genealógica às determinações, às apropriações, às autorizações, aos desvios, às rotas, às relações limitantes estabelecidas, aos moldes que foram sendo desenvolvidos, aprimorados e reproduzidos, para que à essa figura, a "mulher", fossem dados formatos, funções, atributos e ideais indispensáveis ao que é necessário às sociedades masculinas. Suas contribuições são válidas para analisar a construção do gênero como recurso político, democrático, que direciona respostas às demandas estritamente sociais, interessadas, muito embora acopladas às virtudes, que, por seu turno, garantem avaliações que conferem valor aos indivíduos, e, simultaneamente, à ostentação do que se faz necessário para que as sociedades sigam apenas

4 PETRY, "Supondo que a verdade seja uma mulher: para uma ética da diferença a partir de Nietzsche”, p. 4.

${ }_{5}^{5}$ PETRY, "Supondo que a verdade seja uma mulher: para uma ética da diferença a partir de Nietzsche", p. 5. 
dando vazão ao que já fora construído, bem avaliado e benéfico a elas mesmas. Em outras palavras, se naquilo que o indivíduo se torna há o resultado das demandas das sociedades, uma vez que ele mesmo não se acessa a não ser por meio da necessidade de ser denominado, de ser aceito, de ser bem avaliado, de estar de acordo com as virtudes, importa então se ater também àquilo que ele não se torna. Assim, pensar em gênero requer também pensar se a elaboração da ideia de gênero não é instrumento das civilizações para que dicotomias sejam arquitetadas, para que virtudes sejam atribuídas a cada gênero e por cada um deles aceitas e procuradas. Há de se visualizar o acervo no qual o gênero é uma peça fundamental.

\section{Nietzsche: sobre a falta de poder das determinações para as mulheres}

Na obra A gaia ciência (1882), no aforismo 58, Nietzsche adverte que, mais do que compreender o que as coisas são, importa muito mais compreender "como as coisas se chamam", porque o modo como são denominadas exerce o efeito de essência. A respeito desse amálgama, ele argumenta que:

A reputação, o nome, a aparência, o peso e a medida habituais de uma coisa, o modo como é vista - quase sempre uma arbitrariedade e um erro em sua origem, jogados sobre as coisas como uma roupagem totalmente estranha à sua natureza e mesmo sobre a sua pele -, mediante a crença que as pessoas neles tiveram, incrementada de geração em geração, gradualmente se enraizaram e encravaram na coisa, por assim dizer, tornando-se o seu próprio corpo: a aparência inicial termina quase sempre por tornar-se essência e atua como essência! ${ }^{6}$

Desta feita, interessa-nos o exame de Nietzsche sobre o poder das definições, graças à crença na linguagem, nas formulações teóricas dela decorrentes, mais especificamente, interessa-nos pensar, a partir disso, no peso das determinações que "mulher" e "feminino" adquirem tendo em vista compreensões, significados e responsabilidades atribuídas a quem ganha tais designações.

Realizando um salto, para uma obra posterior, Para a genealogia da moral (1887), na $14^{\mathrm{a}}$ parte da primeira dissertação, consideremos uma cena elaborada por Nietzsche, na qual há um diálogo entre alguém que descreve os subsolos úmidos, escuros e mal cheirosos, onde se fabricam ideais na terra, e alguém que vai se enojando com a cena descrita. Se no contexto desta obra é muito mais a fabricação de ideais ascéticos que está posta em questão, por sua vez, em outras obras não faltam cenas e diálogos criados por ele para tratar do mesmo ambiente fétido no qual se dá a elaboração de outros ideais. Neste momento, interessa-me mais especificamente as situações (aforismos) nas quais estão tensionados os ideais forjados para as mulheres e por meio de quais fabricantes elas se formam.

No aforismo 68 de A Gaia Ciência, Nietzsche constrói um diálogo entre um sábio, defensor das mulheres, e seus ouvintes, dois homens que acusam as mulheres de estragarem os jovens através da educação que lhes dão. A situação criada por Nietzsche para compor

${ }^{6}$ NIETZSCHE, A Gaia Ciência, p. 96. 
esta cena é constituída por uma discussão entre os homens a respeito das mulheres, no tocante, mais especificamente, da educação que elas devem ofertar, segundo a avaliação deles. Em função disso, eles discutem a educação que elas deveriam receber, bem como, de como elas mereceriam ser tratadas. Um sábio participa da conversa. A ele foi enviado um jovem, para ser avaliado, para que se averigue se as mulheres têm "estragado" os jovens por meio da educação dada a eles. É por causa da possibilidade de que o estrago esteja ocorrendo que os demais homens reclamam que um outro tipo de educação deva ser providenciado para as mulheres. O sábio, entretanto, defende as mulheres.

É digno de nota que neste aforismo não há como atribuir a Nietzsche qualquer opinião ou posicionamento. Há o que o sábio defende. Há o que é defendido pelos outros homens. Onde está Nietzsche? Há um desafio na leitura dos escritos de Nietzsche: indagar quem e o que está em questão nas ideias que estão sendo mostradas, tensionadas, questionadas, denunciadas. Trata-se de posições suas ou do que já está posto pela tradição, algo que ele provocativamente traz à discussão, sem necessariamente mencionar a autoria? $\mathrm{O}$ aforismo 68 de A gaia ciência é, a meu ver, é um exemplo de toda essa complexidade.

Não obstante, se nas leituras feitas, imediatamente se dá a identificação de Nietzsche com o que está sendo visto no aforismo, é compreensível restar a quem lê apenas concordâncias ou indisposições. Nietzsche poderá, por decorrência, ser citado (pelos misóginos), ou afastado, por ser rechaçado. No caso do aforismo 68 de $A$ gaia ciência, no diálogo entre os personagens, nas oposições entre eles, atribuo a Nietzsche a denúncia de quem são os tipos preocupados em definir e decidir sobre as mulheres, com quais intenções e interesses. Mas há também algo que não decorre deste esforço. O jovem, a ser avaliado pelo sábio, não participa do diálogo, a não ser com seu silêncio e indiferença. Quando o sábio acena para que o jovem o siga, para poder ser finalmente analisado, o jovem não atende ao seu chamado. O jovem, que é educado pelas mulheres, não dá ouvidos ao sábio e sequer participa da discussão, defendendo-se ou defendendo as mulheres. Se acolhermos a problemática que está posta neste aforismo, podemos nos ater muito mais às provocações proporcionadas, quais sejam: quais são as figuras nele colocadas para dizer a respeito do que "são" as mulheres, para tentar delimitar o que elas "devem fazer" e para avaliar se elas cumprem direito suas obrigações? Como as mulheres comparecem e não aparecem nesta cena?

Há um Nietzsche misógino, como à primeira vista poderia ser concluído? Não seria muito mais uma denúncia do funcionamento da sociedade que, mesmo após as determinações efetuadas, segue cuidando das determinações? Trata-se de relações de poderes, mas o domínio de um sobre o outro não é o único recurso. Se a subjetividade não é abalada, o poder de domínio fica sem seu efeito. Creio ser neste sentido que as relações entre mulher e espírito livre podem ser feitas. Segundo Lewis Call, Nietzsche contribui para que não se dê confinamento nas dualidades.

Nietzsche, portanto, forneceu algumas ferramentas importantes para o feminismo pós-moderno: representação negativa para criticar as variedades equivocadas do feminismo e representação afirmativa para celebrar novas possibilidades para as mulheres. Há nos escritos de Nietzsche um verdadeiro arsenal de posições de sujeito feminino. Resta ver como essas posições serão transformadas em uma política significativa; talvez elas sejam mais 
significativas no 'nível individual de práticas micropolíticas e cotidianas de De Lauretis'. Afinal, é aqui que a representação alcança seu significado mais profundo para as mulheres vivas, pois o que significa ser mulher é definido por elas e para elas de maneira imediata ${ }^{7}$.

Ora, há mais do que um jovem não dando ouvidos aos homens. Quando este não dá ouvidos ao sábio, e permanece indiferente e em silêncio na discussão travada, Nietzsche possibilita uma percepção do poder de quem não está na cena, qual seja: o que as mulheres são capazes de criar. O jovem, o que aparece em cena, retrata que o que elas são capazes de criar escapa da obediência que a sociedade tanto preza e exige. Enquanto a sociedade delimita para as mulheres a função de educar (cuidar, professorar, guiar, recusar-se em nome de outrem - abnegar-se), para que as pessoas possam ser transformadas em úteis, confiáveis, obedientes e servis, para que também se dê nelas as delimitações de funções, profissões, papéis, elas, não obstante, são capazes de gerar algo distinto. Vale destacar, também, que a indiferença e a desobediência do jovem minam o poder da discussão sobre o que "é" e o que "deve ser" a mulher. Sem discursos, Nietzsche faz aparecer a capacidade de desprezo a toda a discussão a respeito das obrigações atribuídas às mulheres. A obra realizada pelas mulheres tem um resultado distinto do que fora arquitetado, autorizado, estipulado.

No aforismo 68 de A gaia ciência, a partir do silêncio e da indiferença do jovem educado pelas mulheres, Nietzsche deixa ser perceptível um aspecto que nada condiz com dar razão ou estar de acordo com qualquer um dos personagens. O silêncio, no desfecho da cena, diz muito mais do poder de elaboração do que não está no roteiro, e da falta de poder da sociedade para imputar o que quer que queira, ao menos para todos. Há quem se faça diferente e também faça de modo diferente aquilo que faz. Assim, no aforismo 68 de A gaia ciência, sem qualquer discurso argumentativo, que ofereça vantagens a um dos lados na disputa de ideias acerca do que "é" ou "deveria ser" a mulher, Nietzsche traz à tona a falta de poder da sociedade sobre um tipo que dela faz parte: as mulheres, que são capazes de se elaborar para além do que lhes foi imputado. Neste sentido, ele faz ver o fracasso dos esforços de determinações para as mulheres, bem como os homens se preocupando e se ocupando diante do desafio, importante para eles, de determinação do que elas são e devam ser.

Se o olhar para o que Nietzsche traz estiver antecipadamente preso à necessidade de tomada de posição, graças a qualquer incômodo, inconformidade, ou opinião prévia e fixa, à escolha de um dos lados das dicotomias colocadas (o sábio defensor das mulheres, ou os demais homens, críticos a elas), restaria, então, enxergar nele somente misoginia. Se este for o tema, o destaque ao poder próprio às "mulheres" poderia permanecer intocável, bem como poderia seguir imperceptível a acusação feita sobre o domínio que os homens tentam sempre

\footnotetext{
7 "But against these two dismal realities stands a beautiful possibility: woman as Dionysian, as (un)truth, as free spirit. Nietzsche has thus provided some important tools for postmodern feminism: negative representation to critique the misguided varieties of feminism, and affirmative representation to celebrate new possibilities for women. There is in Nietzsche's writing a veritable arsenal of female subject positions. It remains to be seen how these positions will be transformed into a meaningful politics; perhaps they will be most significant on de Lauretis's 'individual level of micropolitical and everyday practices'. After all, it is here that representation achieves its most profound significance for actual, living women, as what it means to be a woman is defined by them and for them in an immediate way" (CALL, "Woman as Will and Representation: Nietzsche's Contribution to Postmodern Feminismin", p. 127).
} 
ter sobre o que deva ser as mulheres, a despeito de as defenderem ou as atacarem. Faz-se necessário destacar que no aforismo em questão, o sábio, o defensor das mulheres, é o mesmo que defende também uma "natureza" para cada um dos sexos. Neste sentido, ele representa o poder que os homens da ciência, e de outros tipos de saberes, possam querer ter sobre as mulheres. Afinal, segundo o sábio, a despeito do que quer que seja visto como errado nas mulheres, a responsabilidade por isso é dos homens, porque "o homem cria para si a imagem da mulher, e a mulher se cria conforme essa imagem". O defensor das mulheres, o sábio, é quem mais as diminuem, a ponto de alegar que elas são o que são por serem obra dos homens.

Cleverton Barboza e Vanusa Silva compreendem que:

Nietzsche talvez tenha percebido, mais que todos em seu tempo, que a mulher foi submetida ao "tu deves", uma construção filológica com implicações práticas, o nascimento de uma cultura se dá a partir das significações que ela dá ao mundo, a significação dada às mulheres sempre (ou na imensa maioria das vezes) partiu do olhar masculino se impondo como vontade dominante, criando um papel e um ser social inferiorizado ou secundário para a mulher. A partir de ideais masculinos, a imagem da mulher foi sendo lapidada?

No entanto, ao menos no aforismo 68 de A Gaia Ciência, não é Nietzsche quem defende o que é defendido pelo sábio. Mas também os homens que as atacam, os inconformados pelo fato de elas estarem alterando o que lhes fora determinado, não disfarçam a autoridade que querem ter sobre elas, discutindo sobre a necessidade de mudar a educação que deve ser dada a elas, para que não mais "estraguem” os jovens ao educá-los. Mas uma expectativa de poder do homem sobre a mulher já estaria denunciada desde a postura do sábio, seu defensor e analisador do que ela fez. É ainda digno de nota que não há mulheres no aforismo, a não ser um jogo de imagens operacionalizado por Nietzsche, colocando em questão as distintas pretensões de poder dos homens sobre as mulheres, as distintas visões a respeito das mulheres, por decorrência, distintas defesas a respeito de como devam ser tratadas. Mas o personagem indiferente a tudo, o jovem, talvez diga ainda mais sobre o poder da obra das mulheres sobre si mesmas.

Se às mulheres fora estabelecido a função de educar os jovens, eles podem, contudo, serem educados a partir de uma total diferença, e, inclusive, indiferença ao que fora esperado, estipulado, ordenado, programado. Nem perante uma educação, as mulheres necessariamente atendem ao que a elas foi conferido. Em silêncio desfila aí o poder das mulheres de elaboração de si mesmas, a despeito daqueles que querem ter domínio sobre elas. $\mathrm{Na}$ desobediência do jovem, com o viés de indiferença, está o que as mulheres são capazes de fazer, independentemente do que para elas é estipulado.

Acima de todos os personagens que aparecem, paira alguém que sequer precisa compor a cena: as mulheres; as que criam a partir da indiferença poderosa, e, neste caso, também silenciosa - do jovem que não profere discursos como recurso para dizer dos

${ }^{8}$ NIETZSCHE, A Gaia Ciência, p. 100.

9 BARBOZA; SILVA, "Nietzsche, a mulher e o feminino: considerações acerca do espírito livre nas relações de gênero", pp. 1404-1405. 
poderes delas. No descaso do jovem, então, é possível concluir um feito das mulheres, um poder delas, uma força que não é submetida, não cede ao que é determinado, uma capacidade delas de elaborar o que está para além das determinações. Na cena, pode ser perceptível também o afastamento delas; afastadas, mas incólumes, posicionadas à parte de toda a discussão que tenta dar seguimento a um propósito ou obter novos cálculos e novos procedimentos para o domínio. Enquanto estratégias educacionais para o domínio são discutidas pelos homens, as mulheres seguem afastadas da lastimável cena, e ainda assim têm nela sua obra exibida. É o solapamento das autoridades que está em ação. Nas tensões que podem ser interpretadas no modo como Nietzsche traz figuras de mulheres, ou feitos de mulheres, para seus aforismos, há uma discussão bem própria a ele no que tange às bases da política moderna. Nada mais político do que fazer ser exibido um poder destemido, que sequer se põe em discussão.

Ao analisar outros aforismos, Lewis Call, que vê em Nietzsche uma contribuição para um feminismo pós-moderno, um feminismo radical, alega que "não identifica nos escritos de Nietzsche um filósofo reacionário e que a 'misoginia' de Nietzsche surge como parte de um amplo projeto crítico, projeto este de desestabilizar as instituições da modernidade, tendo em vista a preparação para uma nova construção" ${ }^{\text {. }}$.

Relevante também é notar que, no aforismo 68 de A gaia ciência, a mesma acusação que, segundo a tradição filosófica, fora feita a Sócrates (qual seja: ter desviado os jovens) fora também feita às mulheres. Não obstante, no caso da acusação feita às mulheres na cena deste aforismo, não há a pena da ingestão de cicuta. Trata-se de uma sociedade da democracia moderna? No descontentamento, na acusação de estrago feito aos jovens, não repercute a penalidade de morte às mulheres, tal como se deu com Sócrates. Em cena estão quem confia no que os homens são capazes de fazer com as mulheres, quais sejam: o sábio, seu defensor e delimitador, e os demais homens, que discutem acerca da necessidade de alterar as determinações (a educação) para elas. Não seria o efeito do pathos da distância nas mulheres que faz com que nem o sábio obtenha sucesso? $\mathrm{Na}$ defesa ou no ataque às mulheres, é o esforço de determinação delas que segue entre os homens. Seja por meio de saberes, seja por meio de exigências ou de liberdades conferidas a elas, seguiriam prevalecendo exigências que não lhes são próprias, mas que seguem sendo disputadas. Contudo, o que a mulher "é" ou "deveria ser" não tem mais poder.

Vale lembrar que, no primeiro volume de Humano, demasiado bumano (1878) - quatro anos antes da publicação de $A$ gaia ciência - no aforismo 437, Nietzsche denuncia o que Platão teria deixado ${ }^{11}$ a respeito do distanciamento das mulheres do sábio, algo exigido por ele mesmo - no caso, quando Sócrates pede, impaciente, pelo afastamento das mulheres, quando elas atrapalham o silêncio na espera dele pela cicuta.

Enfim. - Há várias espécies de cicuta, e geralmente o destino encontra oportunidade de pôr nos lábios do espírito livre um cálice de veneno - para 'puni-lo', como diz depois o mundo inteiro. O que fazem então as mulheres à sua volta? Elas gritam e lamentam, perturbando talvez o descanso

\footnotetext{
10 "Far from being reactionary, then, his 'misogyny' emerges as part of a wide-ranging critical project. This project is an attempt to destabilize the institutions of modernity in preparation for a new construction" (CALL, "Woman as Will and Representation: Nietzsche's Contribution to Postmodern Feminismin", p. 123).

${ }^{11}$ Segundo o tradutor Paulo César de Souza, na nota 143: Fédon de Platão, 116b, 117c-e.
} 
crepuscular do pensador: tal como fizeram na prisão de Atenas: 'O Críton, manda alguém levar para fora essas mulheres!' - falou Sócrates enfim ${ }^{12}$.

Da ingestão de cicuta, Sócrates não se livrou; seu discurso não conseguiu protegê-lo. Não obstante, ao pensador, ao sábio, ao filósofo, insuportável foi ouvir o lamento das mulheres, ainda que tenha sido um lamento pelo sacrifício da vida dele. Então, ele ordena que elas sejam afastadas. Assim lemos o aforismo 437 do primeiro volume de Humano, demasiado humano: Sócrates bebe cicuta e morre; mas antes, ele exige o afastamento das mulheres. Posteriormente, no aforismo 68 de A Gaia Ciência, Nietzsche volta ao tema. Desta vez, elas seguem vivas, se elaborando e educando os jovens à maneira delas. A cicuta dada a elas não as matara. Elas foram afastadas, mas não perderam poder. A punição não teve efeito. As mulheres nem estão presentes quando aquilo que fizeram está em discussão. Esta discussão não lhes interessa.

A respeito da difícil relação dos filósofos com as mulheres, da pretensão deles à verdade e da relação deles com o dogmatismo, Oswaldo Giacoia retoma, no artigo Nietzsche e o feminino, do prólogo da obra Para além de bem e mal (1886), uma imagem sugerida por Nietzsche, de que "a verdade seja uma mulher". Na análise de Giacoia destaca-se a importância do estilo com o qual Nietzsche elabora tal suposição.

Nas primeiras linhas desse prefácio [de Para além de bem e mal], Nietzsche utiliza-se de uma metáfora, identificando a verdade com uma mulher. Do modo como procuro interpretar o estatuto e o papel dos recursos estilísticos, das imagens e procedimentos retóricos na construção dos argumentos em Nietzsche, julgo poder vislumbrar aqui uma mobilização estratégica da questão do feminino, trazendo-a para o coração mesmo do debate antiplatônico - é bom não esquecer que, para Nietzsche, Platão representa o baluarte ancestral do dogmatismo -, mobilização caracteristicamente nietzscheana, na medida em que combina o recurso à metáfora, relativa à mulher, com os efeitos crítico-corrosivos presentes nas várias formas de humor com que trabalha em seu experimentalismo: o riso, a ironia, a paródia e a caricatura ${ }^{13}$.

No aforismo 68 de A gaia ciência, a cena descrita por Nietzsche diz de uma alteração na relação entre o sábio e as mulheres. O sábio defende as mulheres, mas, ao fazer isso, denuncia a tentativa de domínio sobre elas. Já as mulheres seguem afastadas do sábio e de quaisquer homens que queiram falar sobre elas e delimitá-las. Seguem vivas. Se outrora, na cena do aforismo 437, em Humano, demasiado bumano, o afastamento das mulheres se dá por exigência do sábio Sócrates, julgado e condenado pela acusação de ter "estragado" os jovens, no aforismo 68 de A gaia ciência, quando a acusação de estrago dos jovens recai sobre as mulheres, elas já estão distantes, desta vez pelo poder de sua obra: do descaso do jovem educado por elas, "estragado", desobediente pela via da indiferença à discussão e ao sábio. Elas se afastam inclusive do afastamento requerido pelo Sócrates de Platão, a autoridade de

${ }^{12}$ NIETZSCHE, Humano, demasiado bumano: um livro para espiritos livres, p. 236.

13 GIACOIA, "Nietzsche e o feminino", p. 2. 
outrora. A cicuta para o sábio seguiu tendo efeito. Os sábios seguem se desgastando na posse da verdade. Às mulheres? Não houve a opção pela cicuta. Seguem vivas. Sem mais lamentações (pelo sábio a beira da morte). Sem ressentimentos. Seguem exercendo o poder de elaborarem-se. Assim age o espírito nobre. O afastamento das mulheres da tradição teórica/científica/filosófica/metafísica não significou o enfraquecimento do poder delas na criação de si mesmas, a despeito da preferência dos sábios não ter sido por elas - afinal, foi pela morte, em nome da verdade. Elas seguiram, inclusive sem recusarem o motivo do pedido do afastamento delas: os afetos próprios da vida. Os sábios, sobreviventes, seguiram em busca da verdade e, através dela, do domínio. Há de se pensar o que mobiliza um tipo que nunca cessa de buscar domínio. As mulheres não adentraram nesta cena. Há quem prefira o desafio da criação de si.

Se a tradição filosófica/metafísica/científica sempre necessitou do "é", do ser, da estruturação de uma lógica concatenada para discursos explicativos e delimitadores, a fim de convencer e, assim, alcançar domínio, Nietzsche não oferece o mesmo. Sua genealogia da moral é também uma genealogia da verdade, e, por isso, ele não pode ofertar o mesmo, sob o risco de cair na mesma imoralidade da tradição. Segundo Roberto Machado, a ideia de vontade de verdade em Nietzsche merece ser compreendida também à luz da sua conclusão de que "a genealogia da verdade", feita por ele, "prolonga e completa a genealogia da moral"14. A compreensão de que as ideias trazidas nos aforismos estão sendo por ele defendidas é algo que se dá por parte dos leitores, aturdidos talvez pela necessidade de pressa ou pelo incômodo. Daí, consequentemente, a necessidade de objeção, ou de tomar mais um filósofo como autoridade para seus próprios discursos misóginos. Entretanto, a complexidade de metáforas, de jogos e de cenas faz algo a mais aparecer nos aforismos. São aparições. E lidar com o que aparece não é tão convencional como lidar com a verdade fixa e concatenada pela linguagem e pelos discursos. Em vista disso, cabe a pergunta: a respeito da mulher, qual é a verdade defendida por Nietzsche? Como, a partir dele, tomar posse dela? Por que esta necessidade ronda a leitura? Uma das dificuldades que se sobrepõe está exatamente em se retirar da tradição. Ela ordena o leitor a encontrar um "é" que funcione como conclusão (a ser aceita ou rebatida). Mas se alguma ruminação cuidadosa for possível, apesar do desconforto inicial, nas cenas, nos diálogos, nas interrupções, nas personagens que aparecem, e naquelas que nem precisam se inserir nas discussões, talvez seja possível alguma digestão, ao menos para notar que ali não se encontram as verdades consagradas, defendidas sob o aval de um sábio. Há quem persiga a verdade, creia encontrá-la e tente detê-la. Mas quando nem ela, nem a mulher, estão disponíveis, como o poder da tradição pode ser exercido? Como a necessidade da verdade poderia seguir sendo, de algum modo, a mobilização para todos os poderes?

Com estilo irônico, sem recorrer a discursos previamente arquitetados por argumentações, por concatenações lógicas para convencer, mas na complexidade e riqueza das cenas elaboradas na obra de Nietzsche em seus aforismos, pode ser perceptível o quanto e de que modo a tradição tenta ter poder sobre as mulheres, ora valorizando-as, ora desprezando-as. Ainda no aforismo 68 de A gaia ciência, a partir da defesa que o personagem sábio faz da lei dos sexos - "a natureza do homem é a vontade; a da mulher, a docilidade", e, conforme o que ele explica como "leis dos sexos", não há culpabilidade em qualquer ser

${ }^{14}$ MACHADO, Nietssche e a verdade, p. 85. 
humano por sua existência, mas, no caso da mulher, segundo o sábio, há "dupla inocência", afinal, elas seguem o que os homens criaram para elas. Por isso, elas merecem, segundo o sábio, ser tratadas com brandura, ternura e piedade. Este sábio já não é mais aquele (Sócrates), que pede para que as mulheres sejam afastadas. Ele é mais dócil, "democrático"; ele é compreensivo em relação a elas. A partir de uma teoria, da ideia de "natureza dos sexos", ele defende que elas não têm responsabilidade pelos que são. A mudança do discurso, a propagação de um outro tratamento, mais piedoso e compreensível para com as mulheres, não altera em nada a busca de controle que se tenta ter sobre elas por meio das definições e da defesa do que elas devam ser. Elas fazem aparecer, no entanto, o quanto e pelo que são responsáveis e livres

De todo modo, a sociedade já não precisa condená-las à morte, à ingestão de cicuta, tal como na Grécia fizeram com Sócrates. Pelo contrário, a sociedade segue, na figura do sábio e de outros homens, discutindo como ter poder sobre as mulheres; discutindo, por meio da noção de natureza dos seres, o que elas devem ou deveriam fazer, apesar do pedido de Sócrates de Platão, pelo afastamento das mulheres, ter sido atendido. Contudo, em relação ao que Nietzsche traz no aforismo 68 de $A$ gaia ciência, há poderes na sociedade que também estão em risco, tal como outrora estiveram por causa de Sócrates. Mas, então, desfila triunfante, uma sabedoria que não entra na discussão. Enquanto os homens seguem mobilizados pela necessidade de ter nas mãos aquilo que já existe, para a sua própria evolução e para a preservação da vida - e, por isso, necessitam ter posse, domínio (sobretudo da mulher) -, as mulheres parecem estar mais mobilizadas pelo gozo do poder de se elaborarem, a ponto de poderem desprezar o outro que delas quer tomar posse. Sequer o homem (e o que ele criou) é para elas algo fundamental. Nem quem ataca, nem quem as defende consegue tomar posse delas.

\section{Conclusão}

Vale investigar o que as e os personagens de Nietzsche representam, já que não dizem de ideias suas que devam ser seguidas, mas do que ele é capaz de deixar ser visto ao lançar questões que alteram o efeito da tradição socrático/platônica a respeito da determinação das mulheres, e de quaisquer outras pessoas, por meio dos saberes teóricos. São diagnósticos críticos, com os quais é necessário lidar, na medida em que, mais do que trazer como se deve pensar, os aforismos de Nietzsche denunciam as crenças (e os seus efeitos) em ideias já consagradas. As cenas enojam. Podemos pedir para que deixem de ser descritas. Podemos acusar Nietzsche de misoginia. De todo modo, ele oferece provocações e diagnoses a respeito de como as ideias, noções, ideais, verdades foram criadas e qual a posse que elas possibilitaram. Ao feminismo, o mal-estar gerado merece ser enfrentado. As impressões de misoginia se desfazem diante da percepção de que a autoria do que está posto não é nietzschiana, mas sim da tradição masculina, com fins estritamente gregários. Da parte de Nietzsche, não há nenhum discurso teórico para substituir outros que já perduram, em busca de uma nova verdade absoluta que pudesse ser segurada.

No aforismo 68 de $A$ Gaia Ciência, uma outra forma de cicuta mostra seu efeito no desfecho silencioso e indiferente do jovem, "estragado" desta vez pelo que as mulheres fazem. Assim, a vida (a mulher) se afasta da tentativa de domínio sobre ela, graças ao efeito 
do seu próprio poder de criação permanente sobre si mesma. Trata-se do nascimento de outra cultura? Mas isso requer artistas, pessoas mãe, que engravidam-se de si mesmas. Para quem se distancia dos esforços de domínio e cerceamento da vida não resta qualquer condenação à pena de morte, porque, ao se colocar acima deste poder de domínio sobre a vida, emerge a própria obra, com a qual se confunde, porque nela se justifica. São poderes em relação. Às mulheres do aforismo $68 \mathrm{de} A$ gaia ciência o poder de não dar poder às elaborações da tradição masculina se sobressai. E quando o "é" perde efeito, quando esta verdade da metafísica e da linguagem já não importa, um poder diferente se destaca. São diferenças que importam. Neste aforismo, a obra das mulheres é imune à discussão sobre o que ela é. Nietzsche põe em curso um poder maior que não se deixa capturar pelas autoridades, pelos julgamentos e condenações, porque, em sua filosofia, o poder de elaboração de si é maior do que qualquer outro poder.

\section{Referências Bibliográficas}

BARBOZA, Cléberton; SILVA, Vanusa. "Nietzsche, a mulher e o feminino: considerações acerca do espírito livre nas relações de gênero". In: $18^{\circ}$ Redor Perspectivas Feministas de Gênero: desafios no campo da militância e da prática. Universidade Federal Rural de Pernambuco. Evento realizado entre 24 a 27 de novembro de 2014.

CALL, Lewis. "Woman as Will and Representation: Nietzsche's Contribution to Postmodern Feminismin". In: German Yearbook: Feminist Studies in German Literature \& Culture, vol. 11, 1995, pp. 113-129 (Article). University of Nebraska Press.

GIACOIA, Oswaldo Jr. "Nietzsche e o feminino”. In: Naturęa Humana, São Paulo, vol. 4, $\mathrm{n}^{\circ} 1,2002$.

MACHADO, Roberto. Nietzsche e a verdade. Rio de Janeiro: Rocco, 1985.

NIETZSCHE, Friedrich W. Kritische Studienausgabe [KSA] (15 volumes). Editado por Giorgio Colli e Mazzino Montinari. München: DTV; De Gruyter, 1999.

Genealogia da moral. Trad. Paulo César de Souza. São Paulo: Companhia das Letras, 1999.

Humano, demasiado bumano: um livro para espiritos livres. Trad. Paulo César de Souza. São Paulo: Companhia das Letras, 2000.

Obras incompletas. Trad. Rubens Rodrigues Torres Filho, seleção de Gérard Lebrun. 2 vol. São Paulo: Nova Cultural, 1987 (col. Os Pensadores).

. A Gaia Ciência. Trad. Paulo César de Souza. São Paulo: Companhia das Letras, 2001.

PETRY, Isadora. "Supondo que a verdade seja uma mulher: para uma ética da diferença a partir de Nietzsche". Acesso em 09, março, 2019. Disponível em: 
https://www.blogs.unicamp.br/openphilosophy/2019/03/28/supondo-que-a-verdadeseja-uma-mulher-para-uma-etica-da-diferenca-a-partir-de-nietzsche/.

SCOTT, Joan. "Gênero: uma categoria útil de análise histórica". In: Educação \& Realidade. Trad. de Guacira Lopes Louro. Revisão Tomaz Tadeu da Silva. Porto Alegre, vol. 20, n. ${ }^{\circ}$, jul./dez. 1995, pp. 71-99. 